\title{
Dynamic seismic analysis of bridge using response spectrum and time history method
}

\author{
M. Brinissat ${ }^{1, *}$, R. Kuti ${ }^{1}$, Z. Louhibi ${ }^{2}$ \\ ${ }^{1}$ Széchenyi István University, Department of Mechatronics and Machine \\ Design \\ Egyetem tér 1, 9026 Győr, Hungary \\ ${ }^{2}$ Djillali Liabes University, Department of Civil Engineering \\ Sidi Bel Abbes, 22000, Algeria \\ *e-mail: maram.bsat@gmail.com
}

Submitted: 01/12/2021; Accepted: 19/03/2021; Published online: 22/03/2021

\begin{abstract}
Dynamic analysis is very important to better understand the performance of structural elements of a bridge. For this purpose, a seismic analysis of an Algerian highway bridge designed with the new Algerian seismic bridge regulation (RPOA -2008) was carried out using linear and nonlinear analyses. Therefore, response spectrum, time history analyses were performed to evaluate the seismic responses of the designed bridge. The performance of the designed bridge is assessed using 10 ground motion records. The proposed methodology allows an efficient comparison of the seismic response of the bridge in terms of base shear forces, bending moment and displacements. Finally, the paper concludes with a discussion of the specific outcomes.
\end{abstract}

Keywords: response spectrum; time history; artificial accelerograms; plastic hinge

\section{Introduction}

The northern region of Algeria is in an active seismic zone [1], all bridge structures must be designed to resist potential events in the future. A structure subjected to a violent earthquake may be stressed beyond its elastic limit and behave in a non-linear way. Furthermore, resilience influenced structural performance by three properties; strength, stiffness, and ductility [2]. Due to the elasto-plastic character of reinforced concrete, strength and stiffness degradation may appear either progressively or 
abruptly in various parts of the bridge structure, causing permanent deformation and damage. Consequently, the use of linear elastic analysis becomes insufficient, or require structural elements that would be very costly. In order to create a safer, more efficient design, a nonlinear time history analysis becomes necessary.

In many regions, the number of recording stations for earthquake motion is limited, and we cannot produce a real accelerogram for each region where we wish to build a structure. Therefore, we have to generate artificial accelerograms compatible with a response spectrum envelope meeting building code requirements. The determination of the response spectrum from an accelerogram is a straightforward procedure. Whereas the generation of accelerograms from a design (often simplified) response spectrum is a difficult inverse problem. We must also take into account the geology and seismology of the region studied.

This paper presents a dynamic study of a girder bridge, using the time history method driven by artificial accelerograms. We will also compare linear analyses (response spectrum and time history method) to nonlinear analysis (time history method).

\section{Overview of the analytical methodology and description of the bridge}

\subsection{Analysis methods}

\subsubsection{Response spectrum analysis (RSA)}

Response spectrum analysis is an elastic analysis of dynamic responses of all significant vibration modes within the structure. The method is based on determining fundamental modes of vibration, usually by eigenvalue/eigenvector calculation. The major modes are then amplified according to the earthquake acceleration spectrum used in the analysis. Finally, the modes are combined using a modified form of superposition. It may generally include statically determined differential displacements [3].

\subsubsection{Linear time history analysis 'LTHA'}

In time history analysis, seismic actions retrieved from a strong motion database or generated artificially. Accelerograms from the database should come from conditions similar to the site of interest. When that is not possible (due to lack of records that match) accelerograms may be scaled to match peak amplitude or filtered to adjust its frequency content. In this way, many more acceleration time histories are available similar to the response spectrum analysis method, the structure is assumed to be linear elastic [3]. 
Huang, [4] and various building codes (IBC [5], EuroCode [6]) suggest this analysis must contain a sufficient number (about ten) of accelerograms to obtain a reliable estimate of the effects of seismic action. It must match the response spectrum of the site within certain maximum and minimum limits.

\subsubsection{Nonlinear time history analysis 'NLTHA'}

In this analysis the response of the structure over time is computed by the nonlinear modal time history analysis method. The seismic loading should consist of a temporal description of the ground motion developed for the particular site and preferably representing real earthquakes [3].

\subsection{Bridge description}

A typical bridge in Algeria was selected for this analysis. The highway bridge is a regular, seven discontinuous span of $35 \mathrm{~m}$ in length (Fig. 1). It consists of a reinforced concrete deck-girder system using precast beams (Fig. 2 and 3) isolated by rubber bearings installed below the concrete girder supported on top of the pier cap. The piers bearings were assumed to be fixed in the transverse direction and free in the longitudinal direction.

Its superstructure is a pre-stressed reinforced concrete girder consists of a two way $\mathrm{RC}$ deck slab $11.25 \mathrm{~m}$ wide and supported by fixed-free piers and fixed abutment at each end. The piers have $2 \mathrm{~m}$ diameter and height from 12 to $19 \mathrm{~m}$. Pier P3 (height $=14.73 \mathrm{~m}$ ) was used in our analysis.

The analysis of the bridge was conducted according to Algerian standards (RPOA-2008).

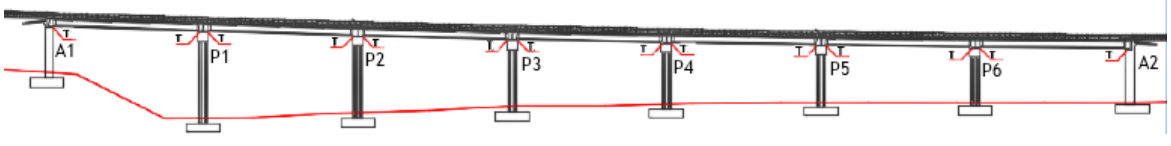

Figure 1. Longitudinal view of the investigated bridge

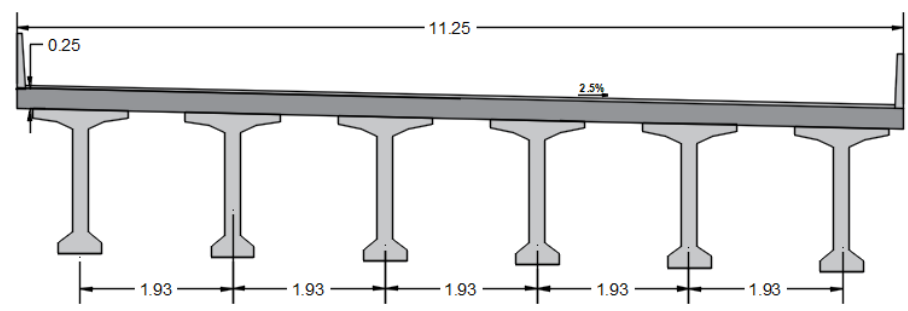

Figure 2. Cross section of the deck 


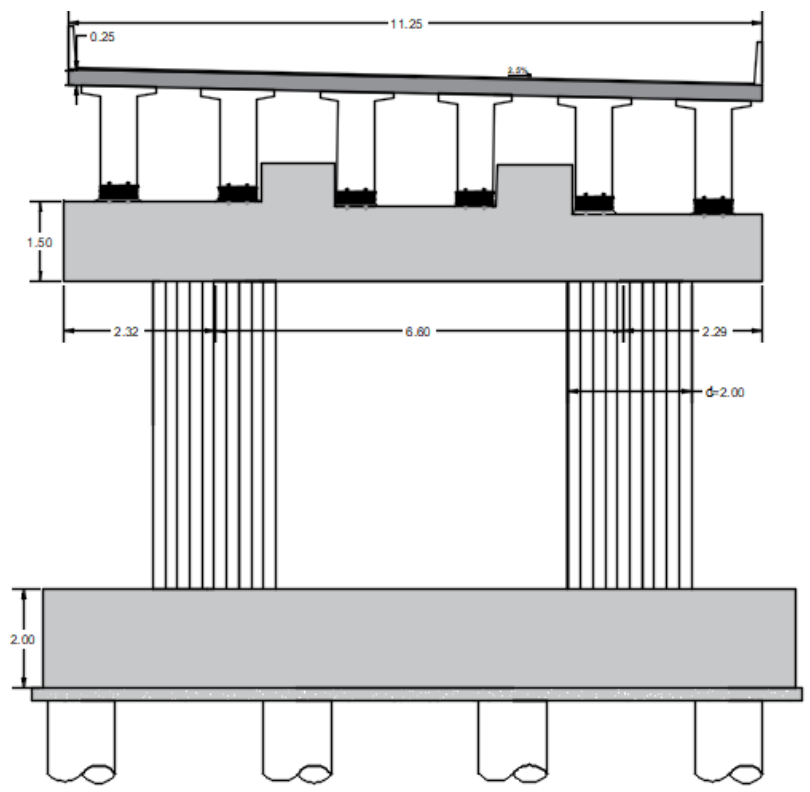

Figure 3. Transversal cross section at pier

\section{Analytical modelling}

\subsection{Ground motion selection}

Without adequate empirical data and considering the importance of the different characteristics of input ground motion, as duration, frequency, site type, etc. 10 real records from varying stations chosen from Boumerdess Earthquake (21 May 2003) were used as input excitation to examine the seismic behaviour of the designed bridge.

For this analysis, real earthquakes (Table 1) compatible with the response spectrum of (RPOA-2008) were generated using SiesmoArtif2021 software [7], considering the local soil conditions.

Fig. 4 shows the response spectra of the scaled and modified accelerograms, compared to the (RPOA-2008) elastic response spectrum. The RPOA classification for this spectrum was: bridge group 02 (important bridge), zone IIa (medium seismicity), soil type $\mathrm{S} 2$.

Fig. 5 shows the selected artificial records. 
Table 1. Seismic records used in the study

\begin{tabular}{|c|c|c|c|c|c|}
\hline$N^{\circ}$ & Magnitude & $\begin{array}{c}P G A \\
(g) \\
\end{array}$ & \begin{tabular}{|c|} 
Earthquake \\
name
\end{tabular} & $\begin{array}{c}\text { Station and } \\
\text { direction }\end{array}$ & Year \\
\hline 01 & 6.8 & 0.322 & \multirow{10}{*}{ Boumerdess } & Boumerdes_EW & \multirow{10}{*}{2003} \\
\hline 02 & 6.8 & 0.365 & & Azazga_L & \\
\hline 03 & 6.8 & 0.224 & & Blida_L & \\
\hline 04 & 6.8 & 0.227 & & El Afroun_L & \\
\hline 05 & 6.8 & 0.308 & & Dar El-Beida_L & \\
\hline 06 & 6.8 & 0.292 & & Hussein Dey_L & \\
\hline 07 & 6.8 & 0.332 & & Keddara1_EW & \\
\hline 08 & 6.8 & 0.310 & & Keddara2_EW & \\
\hline 09 & 6.8 & 0.296 & & Aïn Defla_L & \\
\hline 10 & 6.8 & 0.253 & & Hammam Righa_ & \\
\hline
\end{tabular}

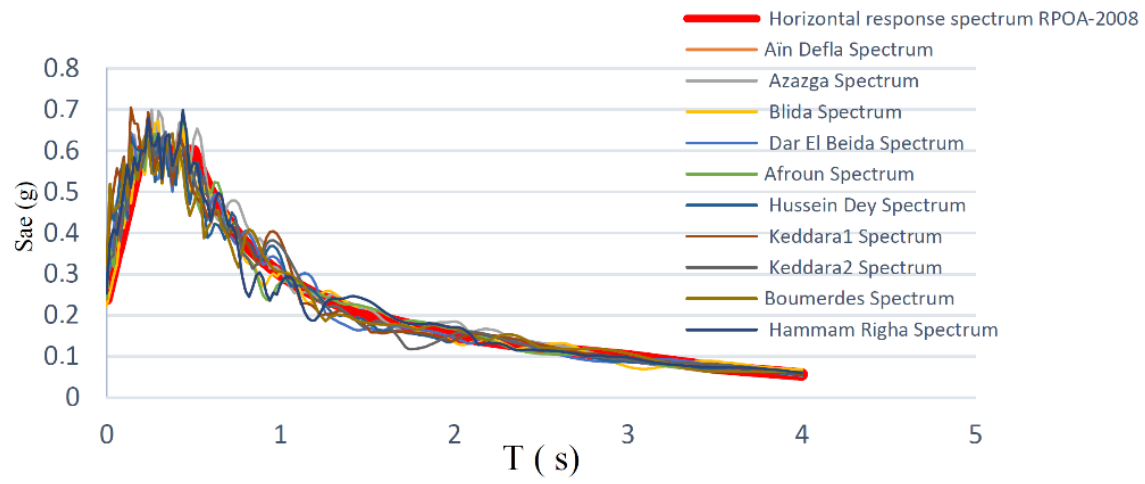

Figure 4. The elastic response spectrum amortized at 5\% of the RPOA compared with the ten generated spectrum 
M. Brinissat et al. - Acta Technica Jaurinensis, Vol. 14, No. 2, pp. 171-185, 2021

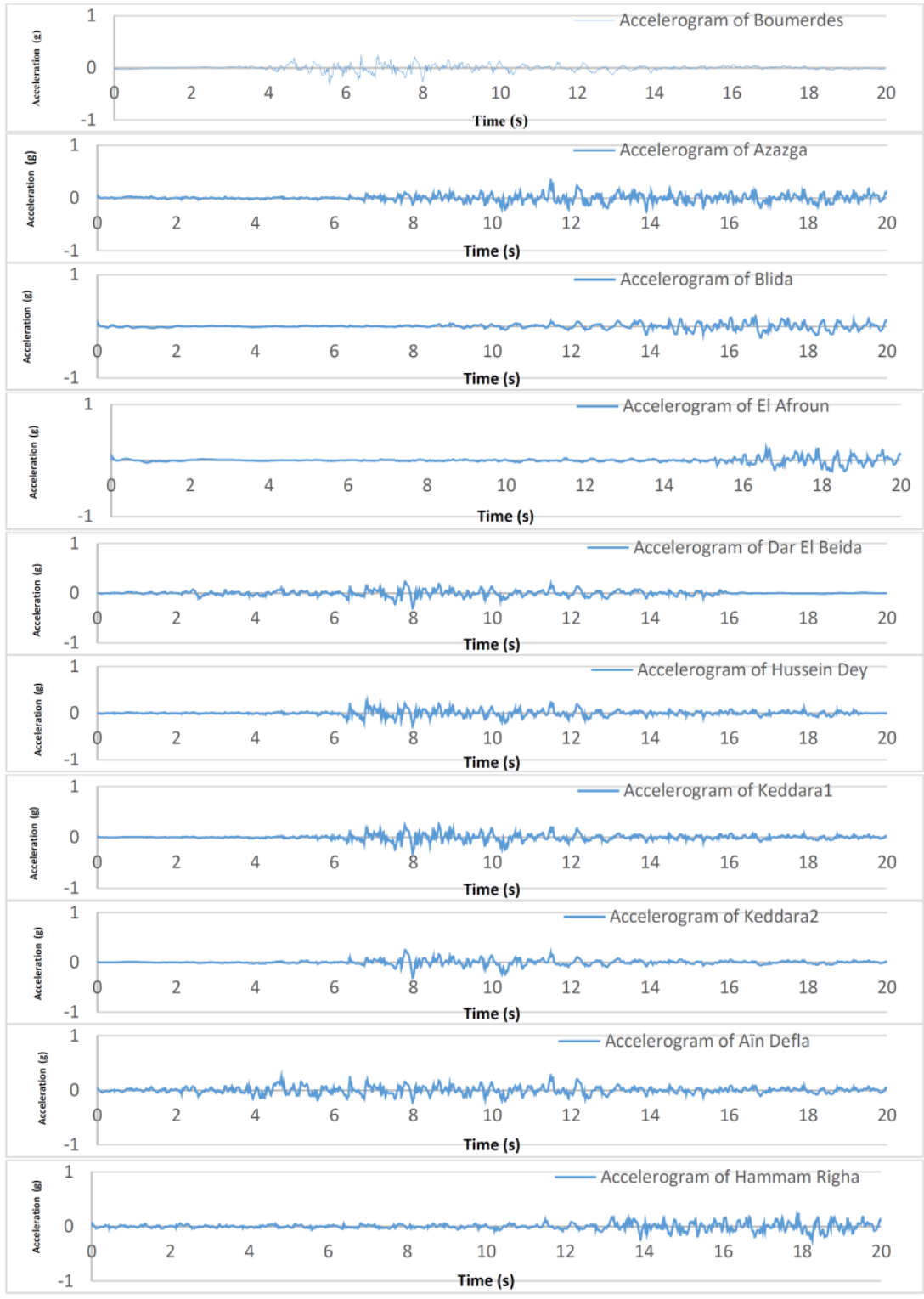

Figure 5. Artificiel grounds motions 
Analytical bridge models

Three-dimensional linear and non-linear analytical models were developed for use in the dynamic analysis. A set of 189 modes are estimated by combining the maximums responses of individual modes using Complete Quadratic Combination (CQC) method. Referring to [8], [9] and [10], the CQC method is adequate for most bridge systems. The design seismic action is calculated using the following combination [6] (see equation (1)).

$$
\mathrm{E}=E_{x} \pm 30 \% E_{y}+30 \% E_{z},
$$

Where; $E_{x}, E_{y}$ and $E_{z}$ are the components of the seismic action in each of the respective directions $\mathrm{x}, \mathrm{y}$ and $\mathrm{z}$.

The deck is modelled with beam and shell elements (Fig. 6). Considering that the superstructure should remain elastic under the effect of seismic excitation, the deck is connected to the bents and the abutments with elastomeric bearings.

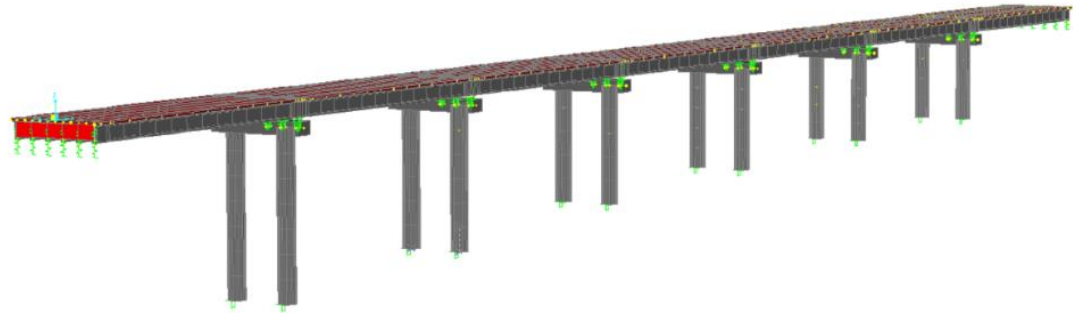

Figure 6. Bridge model

In this study, we consider the nonlinear behaviour of the piers. Therefore, the nonlinearity of the materials constitutes these elements. To simulate the inelastic behaviour of the pier columns, a plastic hinge model is used.

When maximum bending moment is reached, the plastic hinge formed at the base of the pier [11].

Fig. 7 shows the non-linear behaviour of the bridge pier cross-sections and the idealized moment-curvature with axial force due to dead weight. 

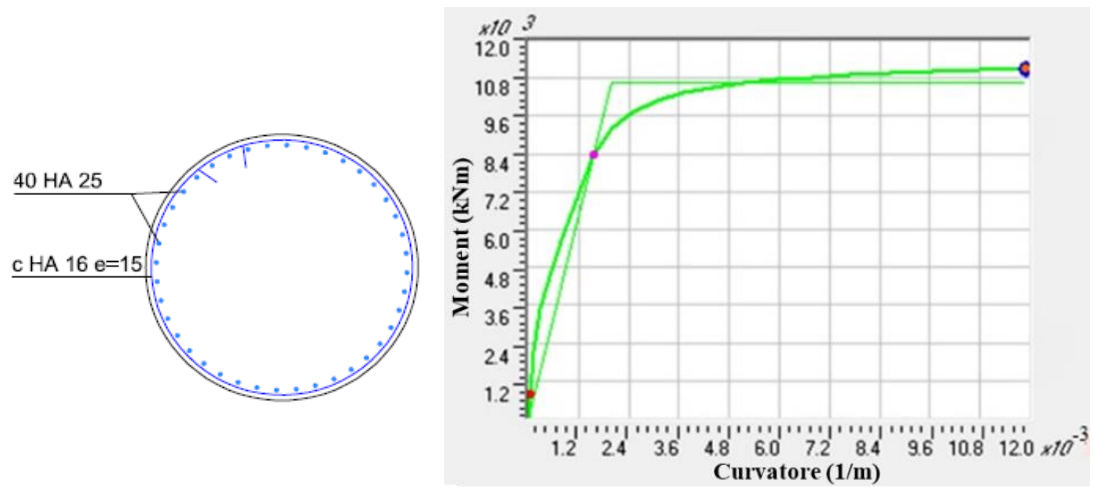

Figure 7. Cross section and moment-curvature relationship of the bridge pier

The nonlinear behaviour of elements is approximated by the use of plastic hinges. In our study, compound compression and bending plastic hinges (P-M) are considered. The data presented in moment-curvature graphs helps us to construct an idealized model of hinge represented by a force-deformation curve to estimate the damage condition curve for each pier. This curve, composed of 5 points A-B-C-D$\mathrm{E}$, represents the behaviour before and after plasticization of the pier and an example is shown in Fig. 8.

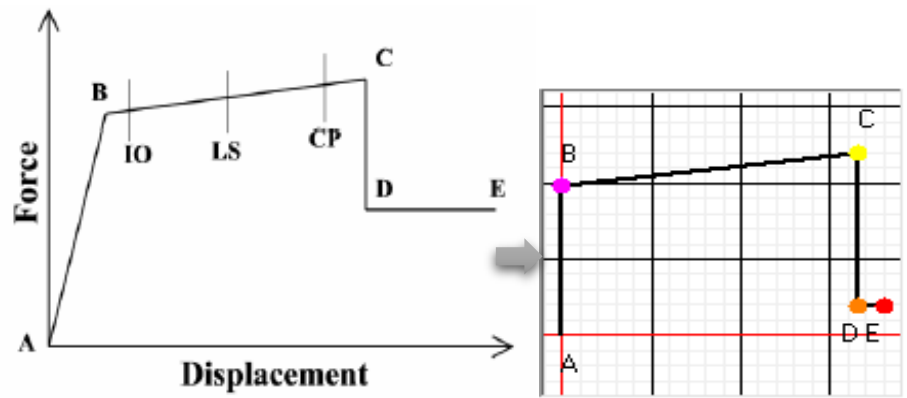

Figure 8. Behaviour law and damage levels used for 3rd pier

The performance levels, matching to the expected damage, are defined (Fig. 8) [12]:

- A: the origin

- B: no plastic deformation 
- IO: Immediate Occupancy

- LS: Life safety

- CP: Collapse prevention

- C, D: no resistance capacity

- E: total failure

Although, Taucer, Spacone, \& Filippou [13] created fiber models for the nonlinear analysis of RC members, in these members the element is subdivided into longitudinal fibers, which use non-linear stress-strain relationships for different materials, such as reinforcing steel, confined concrete and unconfined concrete, etc.

\section{Seismic response of the bridge}

\subsection{Results and interpretation}

For the generated ground motions at different scaled levels of peak ground accelerations (PGA) time history analyses were performed. During seismic excitation the displacement at the top of bridge pier was recorded.

Fig. 9 shows the lateral displacement for NLTHA response of the third pier subjected to the Dar El-Beida earthquake for an illustration.

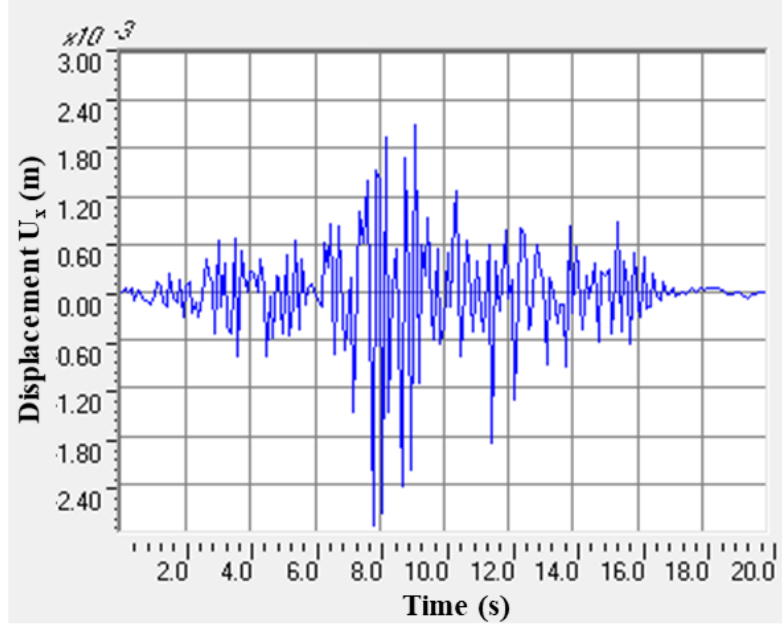

Figure 9. Variation of displacement response of the bridge pier P3 for nonlinear analysis, Dar El-Beida station 
The maximum results are estimated in terms of internal forces; shear force $\mathrm{V}(\mathrm{kN})$ bending moment $\mathrm{M}(\mathrm{kNm})$ and displacement $(\mathrm{m})$. In this analysis, the seismic action is applied in the longitudinal direction of the bridge.

\section{Base Shear $(\mathrm{kN})$}

- Response Spectrum $\quad$ Linear Temporel

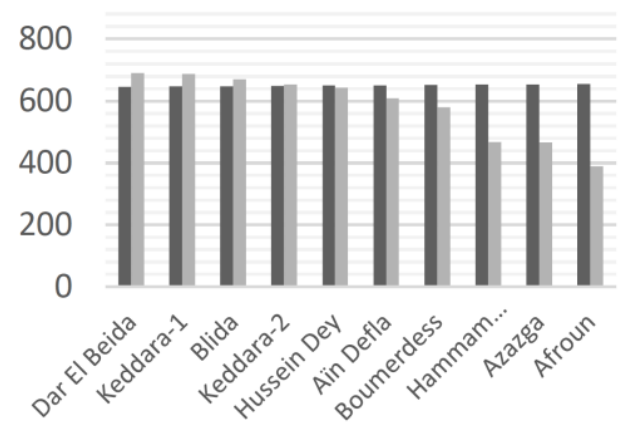

Figure 10. Variation in base shear force at the pier for the linear analysis

\section{Moment $(\mathrm{kNm})$}

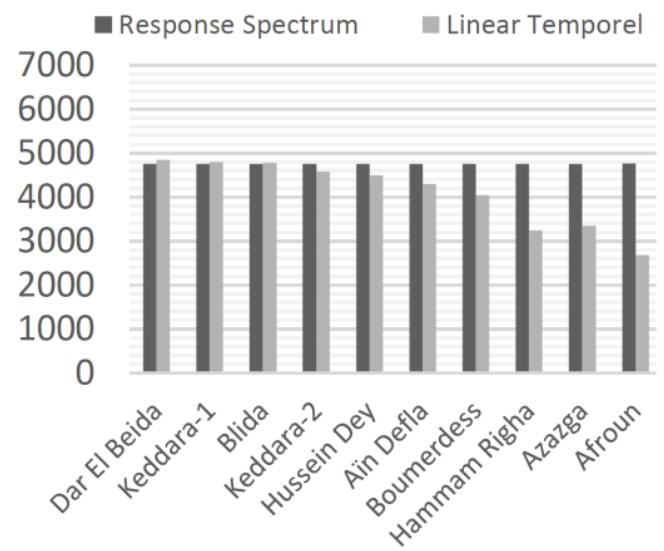

Figure 11. Variation in bending moment at the pier for the linear analysis 


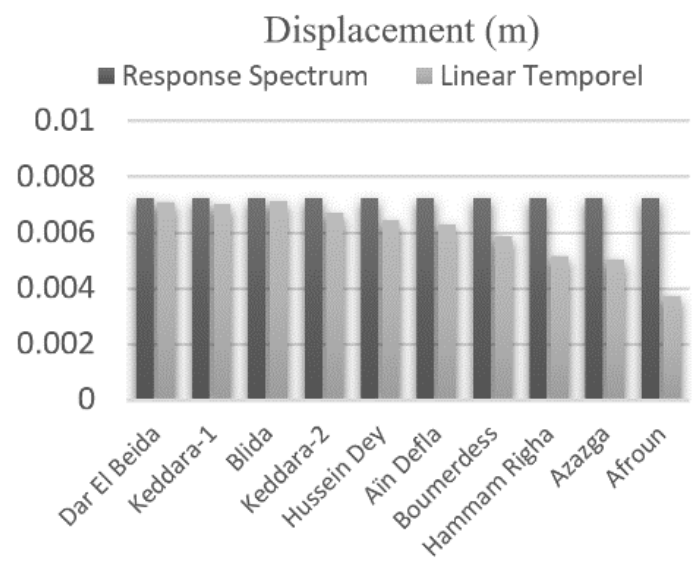

Figure 12. Variation in displacement at the pier for the linear analysis

Fig. 10-12 show that the results of internal forces at the pier section for the linear response spectrum and time history analyses are similar for most of the ground motions. It proves that the generation of modified accelerograms is appropriate.

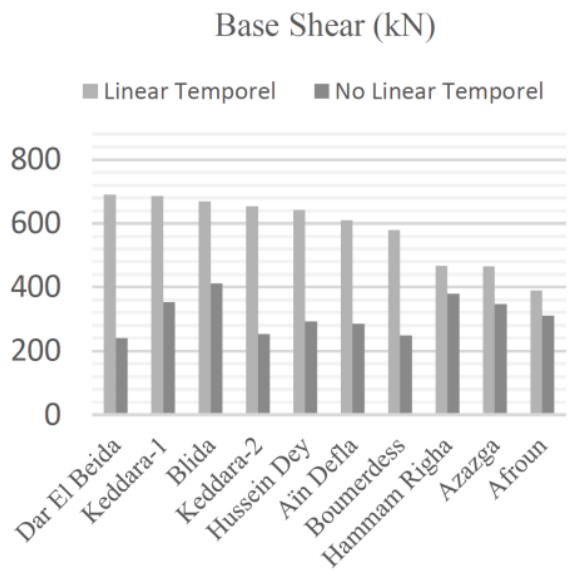

Figure 13. Variation in base shear force at the pier for the linear and nonlinear analyses 


\section{Moment (kNm)}

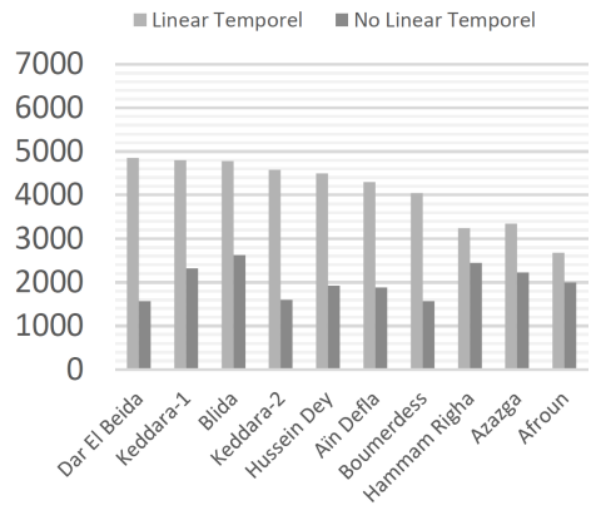

Figure 14. Variation in bending moment at the pier for the linear and nonlinear analyses

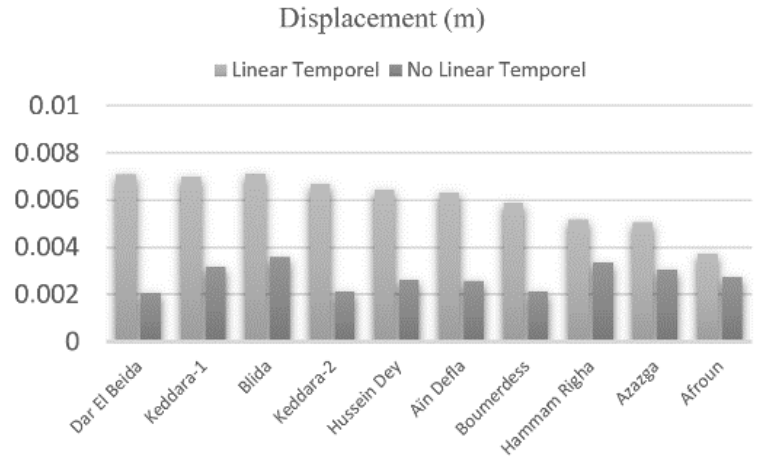

Figure 15. Variation in displacement at the pier for the linear and nonlinear analyses

Fig. 13-15 show that the results of internal forces for the linear time history analysis are larger than that of the nonlinear time history analysis.

It is noted that the results obtained for the nonlinear analysis are more realistic compared to the results obtained for the linear analysis. In this case, a large part of the seismic energy was absorbed by the pier in form of plasticization energy of the tensioned reinforcement and crushing failure of the confined concrete. Therefore, 
the ductility of the pier that appears in strong (amplified) earthquakes is better represented by the non-linear model.

\section{Conclusions}

To better show the differences between the linear analysis and the nonlinear analysis, a comparative study has been produced considering a reinforced concrete bridge.

This paper illustrates the results of the dynamic seismic analysis study and is aimed to develop the seismic response based on numerical simulations for typical Algerian bridge. The bridge designed with the new Algerian seismic bridge regulation, and a great number of accelerogram records from Algerian earthquake major event were selected.

A response spectral analysis response has been carried out, and for this type of analysis an elastic response spectrum from the Algerian seismic regulations characterizing the actions of the earthquake was developed. Furthermore, a nonlinear time history dynamic analysis was then performed to discover the capacity behind the no elastic states.

The main results through this analysis are the following:

- The response spectrum analysis is an approximate approach used to evaluate the maximum value of internal forces.

- Considering nonlinearities at the pier section reduce the internal forces and displacement compared to linear analysis.

- The nonlinear time history method produced a more realistic results of bridge behaviour compared to the linear method. It is usually recommended for geometrically complex bridges.

\section{References}

[1] Y .Mehani,A. Kibboua et al, Seismic Performance Analysis Of An Irregular Existing Building Using The Future Seismic Code RPA 2018 And Non Linear Dynamic Analysis, in 10th International International Civil Engineering Conference ,Pakistan, 2019 [cited 2021-03-19].

URL https://www. researchgate.net/publication/331375552

[2] O. K. Kegyes-Brassai, R. P. Ray, Earthquake Risk Assessment - Effect of a Seismic Event in a Moderate Seismic Area, Acta Technica Jaurinensis 9 (1) 
(2016) pp. 1-15.

doi: https://doi.org/10.14513/actatechjaur.v9.n1.383

[3] RPOA, Algerian seismic regulation code for bridge structures. Ministry of Public Works, Algeria, 2008, in French.

[4] K. Huang, Minimum Number of Accelerograms for Time-History Analysis of Typical Highway Bridges, Master's Thesis, Concordia University (2014) [cited 2021-03-19].

URL

https://spectrum.Iibrary.concordia.ca/978808/1/Huang_MASC F2014.pdf

[5] IBC, The International Building Code, International Code Council, Virginia, USA, 2003.

[6] K. Basil, EUROCODE 8 - PART 2. SEISMIC DESIGN OF BRIDGES. [cited 2021-03-19].

URL

https://eurocodes.jrc.ec.europa.eu/doc/WS2008/Kolias_2008 .pdf

[7] SeismoArtif, Seismosoft Earthquake Engineering Software Solutions (2021) [cited 2021-03-19].

URL https://seismosoft.com/products/seismoartif/

[8] E. L. Wilson, A. Der Kiureghian, E. P. Bayom, A Replacement for SSRS Method in Seismic Analysis, Earthquake Engineering and Structural Dynamics 9 (1981) pp. 187-192.

doi: https://doi.org/10.1002/eqe.4290090207

[9] E. L. Wilson, Static and Dynamic Analysis of Structures, Computers and Structures I (2009) [cited 2021-03-19].

URL http://www.gbv.de/dms/tib-ub-hannover/627175295.pdf

[10] C. Menun, D. Kiureghian, A Replacement for the 30\%, 40\%, and SRSS Rules for Multicomponent Seismic Analysis, Earthquake Spectra 14 (1) (1998) pp. 153-163.

doi: https://doi.org/10.1193/1.1585993 
[11] M. Priestley, F. Seible and G. Calvi, Seismic Design and Retrofit of Bridges (1996).

[12] F. Cherifia, F. Taouche-Khelouia et al., Seismic Vulnerability of Reinforced Concrete Structures in Tizi-Ouzou City (Algeria), 1st International

Conference on Structural Integrity (2015).

doi: https://doi.org/10.1016/j.proeng.2015.08.037

[13] F. F. Taucer, E. Spacone, F. C. Filippou, A Fiber Beam-Column Element for Seismic Response Analysis of Reinforced Concrete Structures (1991) [cited 2021-03-19].

URL http://dinochen.com/attachments/month_1407/k11.pdf 